\title{
Comparing High-Intensity Interval Training (HIIT) and Continuous Training on Apelin, APJ, NO, and Cardiotrophin-1 in Cardiac Tissue of Diabetic Rats
}

\author{
Mostafa Sabouri $\mathbb{D}^{1,2}$ Javad Norouzi, ${ }^{1,2}$ Yashar Zarei, ${ }^{1}$ Mojtaba Hassani Sangani, ${ }^{1}$ \\ and Babak Hooshmand Moghadam ${ }^{1}$ \\ ${ }^{1}$ Department of Exercise Physiology \& Health Science, University of Tehran, Tehran, Iran \\ ${ }^{2}$ Oxygen Sports Medical Center, Tehran, Iran \\ Correspondence should be addressed to Mostafa Sabouri; mostafasaboory@ut.ac.ir
}

Received 30 June 2020; Revised 18 August 2020; Accepted 20 August 2020; Published 28 August 2020

Academic Editor: Janet H. Southerland

Copyright $\odot 2020$ Mostafa Sabouri et al. This is an open access article distributed under the Creative Commons Attribution License, which permits unrestricted use, distribution, and reproduction in any medium, provided the original work is properly cited.

\begin{abstract}
Background and Aims. Exercise activity is an important method for managing type 2 diabetes. This investigation examined the HIIT and continuous training on apelin, APJ receptor, NO, and cardiotrophin-1 in the cardiac tissue of diabetic rats. Methods. The animals were categorized into 3 groups of HIIT, continuous (CO), and control (C) (all animals were sacrificed immediately and 2 days after exercise training period). Rats underwent the treadmill exercise program either HIIT (12 bouts at $90-95 \%$ of $\mathrm{VO}_{2}$ max with $60 \mathrm{~s}$ rest at $50 \%$ of $\left.\mathrm{VO}_{2} \max \right)$ or $\mathrm{CO}\left(60-65 \% \mathrm{VO}_{2}\right.$ max for $40 \mathrm{~min}$ ). Protocols performed 5 days per week for 8 weeks. Apelin, APJ receptor, NO, and cardiotrophin-1 protein expressions were measured using the Western blotting method in the left ventricle. Results. Immediately after HIIT and $\mathrm{CO}$ exercise protocols, apelin and CT-1 protein showed a significant difference in contrast by the C-0 group $(p<0.01)$. However, $N O$ values were substantially higher in HIIT-0 compared to C-0 and CO-0 groups rats $(p<0.01)$. After two days of exercise protocols, apelin and NO protein showed a significant increase in HIIT and CO groups in contrast to the $\mathrm{C}$ animals $(p<0.01)$. Moreover, APJ and CT-1 protein significantly upregulated in CO-2 and HIIT-2 compared to the other groups $(p<0.01)$. Conclusions. This study indicates that exercise training, despite the type, is an efficient method to modify apelin, APJ receptor, NO, and cardiotrophin-1 values in animals with type 2 diabetes.
\end{abstract}

\section{Introduction}

Type 2 diabetes mellitus (T2DM) is distinguished as a metabolic dysfunction described by high-blood glucose in relation to comparative insulin deficiency and resistance of insulin [1]. T2DM is an extremely widespread disease and it is suggested that in 2040, about 642 million persons will suffer from it [2]. Additionally, it has been shown that diabetes is linked with crucial complication and health problems, like cardiovascular disease, nephropathy, and muscle atrophy [3].

Apelin, identified as an adipokine, is potentially upregulated by insulin, and increment of its values has been detected in obesity, insulin resistance, and T2DM in both humans and animals [4]. Moreover, apelin applies its function through activating the APJ, angiotensin receptor-related G proteincoupled receptor [5]. Various tissues such as muscles, adi- pose, lung, and cardiovascular system expressed apelin and APJ $[6,7]$. However, increasing evidence emphasizes that apelin plays a useful role in metabolic dysfunction and has antiobesity and antidiabetic functions $[8,9]$. In this regard, several animal types of research have been shown the effective role of apelin-APJ signaling in obese/diabetic conditions [10]. Furthermore, the dysfunction of the apelin-APJ system in diabetes and cardiovascular disorders induced reduction and increment of vasodilatation and vasoconstriction responses, respectively [11-13]. Apelin peptides through stimulation the release of nitric oxide (NO) cause endothelium-dependent vasorelaxation; by contrast, endothelial NO synthase (eNOS) inhibitor could almost eliminate this effect $[12,14]$. Therefore, it seems that apelin may have a vasodilatation role through activation of $\mathrm{NO}$ pathway. Cardiotrophin-1 (CT-1) belongs to the interleukin-6 (IL-6) 
of cytokines that contributed in energy metabolism and induced hypertrophy in cardiomyocytes $[15,16]$. Interestingly, the lack of CT-1 in animals improved insulin resistance, obesity, and dyslipidemia; by contrast, long-term administration of CT-1 diminished bodyweight and ameliorate insulin resistance in obese mice $[15,17]$. Although CT-1 might contribute to insulin sensitivity [15] and improving metabolic disorders [18], its function in the metabolism of glucose and lipid is still unclear.

In addition, regular exercise training has been recognized as effective intervention methods in order to prevent and manage metabolic disorders such as diabetes. Exercise training by stimulating muscle glucose uptake may maintain chronic glycemic control [19] in T2DM and beneficial in decreasing diabetic complications [20]. Previous researches have shown that exercise training could enhance apelin and APJ values in obese individuals and animals $[4,21]$. Moreover, in one study, CT-1 levels were substantially different between trained and untrained subjects [22]. However, after 8 to $10 \%$ weight loss, CT-1 values have not shown significant change [23]. Nevertheless, the level of participation of diabetics in exercise activities remains low due to time deficiency and difficulty in exercise programs [24, 25]. In this regard, high-intensity interval training (HIIT) is a choice that may by a shorter duration could provide the same or larger benefit than continuous training by moderate exercise for metabolic health [26]. Prior researches have found different results in comparison to HIIT and continuous training T2D [27, 28]. Furthermore, the researches about the comparison of HIIT and CO training on apelin/APJ system, NO, and CT-1 in diabetic rats are limited. Thus, we investigate the effect of HIIT and $\mathrm{CO}$ on apelin, APJ, NO, and, CT-1 in the cardiac tissue of diabetic rats.

\section{Procedures}

2.1. Animals. Male Wistar rats $(n=40$; age $=12$ weeks and weight range of 220-240 g) were obtained from the Animals Center of Pasture Institute of Iran. Animals were housed in the Exercise Physiology Department, at the University of Tehran $\left(12 / 12 \mathrm{~h}\right.$ light/dark cycle at $22^{\circ} \mathrm{C}$ and $\left.\mathrm{RH}=45 \%\right)$. Three to five rats were in glass cages with a lid and dimensions of $25 \times 27 \times 43 \mathrm{~cm}$, which have free access to standard water and food. After 2 weeks of acclimatization period to the new environment, 4 rats were selected as the pilot group and diabetes was make through injection of streptozotocin (STZ), and they were examined for preliminary studies and the ability to perform HIIT and continuous training protocol. After a pilot study, animals were randomly separated into three groups: HIIT (HIIT), continuous training (CO), and control group (C).

2.2. Induced Diabetes. Following acclimatization time (one week), diabetes was induced through intraperitoneal injection of streptozotocin $(\mathrm{STZ})(50 \mathrm{mg} / \mathrm{kg})$, solved in citrate buffer ( $\mathrm{pH}$ 4.5). Two days after STZ injection, fasting blood glucose was determined via a small nick in the tail in order to confirm the diabetes animal model. Diabetes rats represented blood glucose levels up to $300 \mathrm{mg} / \mathrm{dL}$.
2.3. Exercise Training (HIIT and CO Protocols). After STZinduced diabetes and familiarization week to treadmill exercise $(10 \mathrm{~min}$, speed $10 \mathrm{~m} / \mathrm{min}, 5$ days/week), animals performed each of HIIT or CO protocols. The HIIT training contains 12 bouts of $1 \mathrm{~min}$ running with $90-95 \%$ of $\mathrm{VO}_{2}$ max and 60 s rest at $50 \%$ of $\mathrm{VO}_{2}$ max with $20 \mathrm{~m} / \mathrm{min}$ speed in the beginning week, which regularly elevated to $30 \mathrm{~m} / \mathrm{min}$ in the 8th week. Animals in the CO carry out $40 \mathrm{~min}$ of treadmill running training with a constant speed of 60 $65 \%$ of $\mathrm{VO}_{2} \max$ throughout the whole training period [29]. It should be noted that control animals have not performed any exercise training. Moreover, $5 \mathrm{~min}$ was considered for warmup and cool down. To motivate the exercise animals to run continuously, sessions of mild shock (intensity $=0.5 \mathrm{~mA}$ ), which do not create stress on rats, were utilized.

According to previous studies, exercise capacity has been measured before the exercise training $[2,30]$. In short, the rats were running at $6 \mathrm{~m} / \mathrm{min}$ intensity on a graded treadmill at $15^{\circ}$ inclinations. Then, the speed increased every 3 minutes by $3 \mathrm{~m} / \mathrm{min}$. This increase continued until the rats became exhausted. The whole distance traveled by rats was considered as exercise capacity.

2.4. Tissue Preparation. Immediately and after 2 days of the last training session, animals were anesthetized (ketamine $(90 \mathrm{mg} / \mathrm{kg})$ and xylazine $(10 \mathrm{mg} / \mathrm{kg}))$, and the hearts were obtained immediately, frozen in liquid nitrogen, and kept at $-80^{\circ} \mathrm{C}$ for next analysis [31].

2.5. Western Blotting. The protein content of apelin, APJ, NO, and cardiotrophin-1 was measured using western blotting Tanique as with previously performed by other researches $[2,3,32]$. The frozen cardiac tissues were homogenized in $1 \mathrm{ml}$ of lysis buffer $(50 \mathrm{mmol} / \mathrm{L}$ Tris- $\mathrm{HCl} \mathrm{pH} \mathrm{7.4,}$ $1 \% \mathrm{NP}-40,0.25 \%$ sodium deoxycholate, $150 \mathrm{mmol} / \mathrm{L} \mathrm{NaCl}$, $1 \mathrm{mmol} / \mathrm{L}$ EDTA, $1 \mathrm{mmol} / \mathrm{L}$ phenylmethylsulfonyl fluoride, $1 \mathrm{mmol} / \mathrm{L} \mathrm{Na} 3 \mathrm{VO} 4$, and $1 \mathrm{mmol} / \mathrm{L} \mathrm{NaF}$ ) and incubated at $4^{\circ} \mathrm{C}$ for $30 \mathrm{~min}$, followed by centrifugation at $10,000 \mathrm{~g}$ at $4^{\circ} \mathrm{C}$ for $20 \mathrm{~min}$. The lysates were collected, and the protein concentration was determined using the Bradford Assay kit. Equal amounts of protein were loaded on $10 \%$ polyacrylamide and then transferred to polyvinylidene difluoride membrane (Roche, UK). Next, the membranes were incubated with primary antibodies overnight at $4^{\circ} \mathrm{C}$, then secondary antibody (anti-goat or anti-rabbit IgG conjugated to horseradish peroxidase). Enhanced chemiluminescence (ECL) detection kit was used for the detection of antigenantibody complexes. Images were quantified using ImageJ 1.63 software.

2.6. Statistical Analysis. Statistical data were shown as mean \pm SD. One-way ANOVA has been used to detected differences among groups with the SPSS software (21.0 version). $p \leq 0.01$ was considered as a significant statistical level.

\section{Result}

Previous reports suggest that microinjection of streptozotocininduced diabetes in the rat $[1,3]$ two days after surgery 
showed that blood glucose levels are more than $300 \mathrm{mg} / \mathrm{dl}$ in all animals (Table 1). Additionally, bodyweight represented in Table 1.

\subsection{Apelin and APJ Protein Expression in HIIT and CO} Groups in the Left Ventricle Tissues in Diabetic Rats. As presented in Figure 1(b), there is a considerable improvement in HIIT-0, CO-0, and HIIT-2, CO-2 groups compared to C-0 and $\mathrm{C}-2$ groups in apelin protein content $(p<0.001)$. Also, the results showed that no substantial difference has been found between apelin protein in HIIT and CO groups immediately and 2 days after the last exercise session $(p \geq 0.01)$. Moreover, although HIIT and CO protocols showed an increase in APJ protein expression compared control group, nevertheless only CO- 0 and CO- 2 showed significant difference compared to the HIIT-0, HIIT-2, C-0, and C-2 groups $(p<0.01$, Figure 2(c)).

\subsection{NO and CT-1 Protein Expression in HIIT and CO Groups} in the Left Ventricle Tissues in Diabetic Rats. The data demonstrate that NO protein in the HIIT-0 group was considerably higher than in C-0 and CO-0 group rats $(p<0.01$, Figure 1(b)), while there are no statistical differences of NO protein among CO-0 and HIIT-0 rats. Furthermore, both HIIT and CO exercise training significantly improved NO levels compared to $\mathrm{C}$ diabetic rat group after 2 days $(p<0.01$, Figure 1(b)). Additionally, CT-1 protein was considerably increased in HIIT-0 and CO-0 groups compared to the C-0 group ( $p<0.01$, Figure $1(\mathrm{c})$ ), whereas CT-1 protein content was significantly elevated in HIIT-2 in comparison to compared C-2 and CO-2 $(p<0.01$, Figure $1(\mathrm{c}))$. No differences in changes of CT-1 protein were found among HIIT and CO rats immediately and after 2 days of the last exercise session. Moreover, it should be noted that HIIT had a greater effect on CT-1 than $\mathrm{CO}$ in diabetic rats.

\section{Discussion}

T2DM, as a metabolic disorder, has shown to damage different organs through micro and macrovascular injuries as well as compromising the life of quality of the diabetes population [32]. Moreover, regular exercise training is considered as a nonpharmacological method in managing and preventing of type II diabetes. In this regard, we used the T2DM animal model to investigate the effect of HIIT and CO protocols on apelin, APJ, NO, and cardiotrophin-1 in the cardiac tissue.

Our results found that CO and HIT upregulated apelin protein values in left cardiac ventricular in diabetic animals. Additionally, a substantial development was observed in APJ protein in CO-0 and $\mathrm{CO}-2$ in diabetic rats. Prior researches reported that apelin might relate to T2DM [33] and might contribute to insulin sensitivity and metabolism of glucose [33, 34]. Moreover, apelin levels in diabetes patients have a direct relationship with the amount of physical activity [35]. In line with our results, in obese mice, exercise training in hypoxic conditions stimulates the expression of apelin/APJ in the skeletal muscle [21]. In another study, apelin mRNA in the myocardial and aorta has been shown to be increased following aerobic training in the hypertensive animals [36]. Apelin stimulation by exercise training has not yet been fully clarified. Although exercise appears to stimulate a polybeneficial adaptation in the cardiovascular system, growth in apelin seems to be a response to exercise adaptation in the cardiovascular system [36]. Moreover, according to previous studies, it seems that exercise training through insulin signaling pathway, PI3K [37], and AKT phosphorylation [38] induced skeletal muscle apelin expression in T2DM $[38,39]$.

Furthermore, many types of research have found a reduction of apelin values in response to exercise training in the T2DM state. In this regard, in an animal's model, longterm aerobic training alleviated apelin/APJ in the fat and muscle tissues [40]. Sheibani et al. [41] and Krist et al. [42] reported that exercise training could diminish the apelin value and apelin mRNA in plasma and fat tissue, respectively, in obese individuals and impaired glucose-tolerant patients. It seems that exercise training has a varied impact on apelin/APJ expression in various organs, like the skeletal muscle, adipose, and cardiac, which indicates that distinct signaling pathways control apelin and APJ expression in different organs. Therefore, more researches are needed to better comprehend exercise training's impacts on apelin/APJ production in various organs in diabetic people.

Disruption in the apelin/APJ system resulted to decrement vasodilatation and improved vasoconstriction responses described in diabetes and cardiovascular dysfunctions [11, 13, 43]. Apelin triggering the release of nitric oxide (NO), which not only plays an essential role in vasomotricity but also in skeletal muscle glucose uptake. A number of studies showed NO availability in both animal and human type 2 diabetic subjects $[44,45]$. Our data showed that both HIIT and $\mathrm{CO}$ protocols induced increases in myocardial NO protein in diabetes rats as previous researches found. In this regard, 7 weeks of exercise training reversed endothelial impairment through the increment of NO production in the T2DM animal model [46]. Furthermore, Laher et al. $[47,48]$ indicated that long-term wheel running improved endothelial function in diabetic mice, although insulin and blood glucose have not changed. According to the current study and previous studies, exercise seems to act an essential role in ameliorating endothelial function, especially in diabetics. An increase in nitric oxide has led to improved glucose uptake and the sensitivity to insulin in diabetics. Besides, it seems that the apelin/eNOS axis has been implicated in processes such as glucose uptake [38] and vascular functions [13, 14], and not surprising that this axis dysfunction is associated with diabetes. The exact mechanism of the increase in nitric oxide through apelin is not clear. However, this increase appears to be due to phosphorylation of the PI3K/Akt/eNOS pathway [49]. The present study also showed that intense exercise had a greater effect on increasing nitric oxide in diabetic mice, which indicates the importance of the role of exercise intensity. In line with our results, Chavanelle et al. reported intense exercise training to have a greater impact on skeletal muscle Glut 4 content and blood glucose in both healthy and obese mice [50].

Moreover, we present in that CT-1 protein value improved substantially in training groups (HIIT-0 and CO- 
TABLE 1: Bodyweight, serum glucose, and weight of animals in different rat groups.

\begin{tabular}{lcccc}
\hline Group & Preweight $(\mathrm{kg})$ & Postweight $(\mathrm{kg})$ & Preglucose $(\mathrm{mg} / \mathrm{dl})$ & Postglucose $(\mathrm{mg} / \mathrm{dl})$ \\
\hline C-0 & $239 \pm 26.7$ & $305 \pm 14.44$ & $377.6 \pm 40.41$ & $334.19 \pm 27.94$ \\
C-2 & $233 \pm 24.78$ & $295.2 \pm 18.26$ & $369.6 \pm 39.04$ & $350.13 \pm 18.75$ \\
HIIT-0 & $237.5 \pm 21.22$ & $205.6 \pm 8.26$ & $319.3 \pm 34.45$ & $300.8 \pm 12.98$ \\
HIIT-2 & $236.3 \pm 26.5$ & $207.5 \pm 16.52$ & $330.6 \pm 35.97$ & $297.18 \pm 22.15$ \\
COT-0 & $223.83 \pm 29.57$ & $212 \pm 13.75$ & $348.16 \pm 27.43$ & $305.19 \pm 31.85$ \\
CO-2 & $229.83 \pm 18.73$ & $214.86 \pm 12.45$ & $360.16 \pm 36.33$ & $315.17 \pm 18.95$ \\
\hline
\end{tabular}

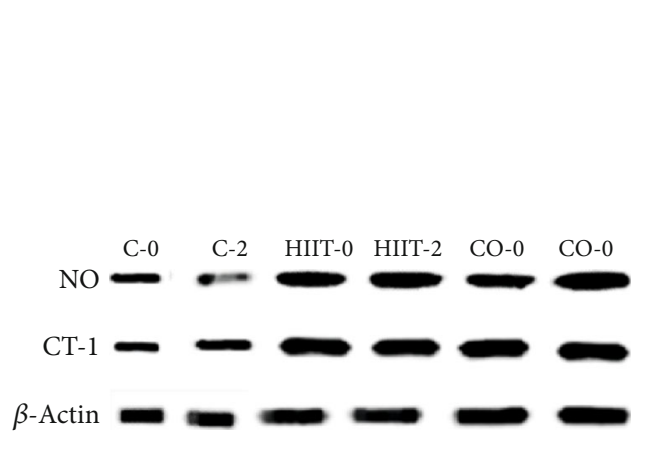

(a)

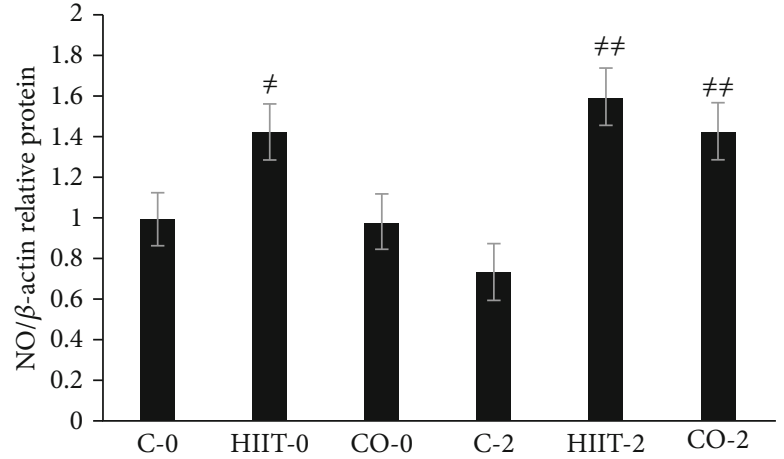

(b)

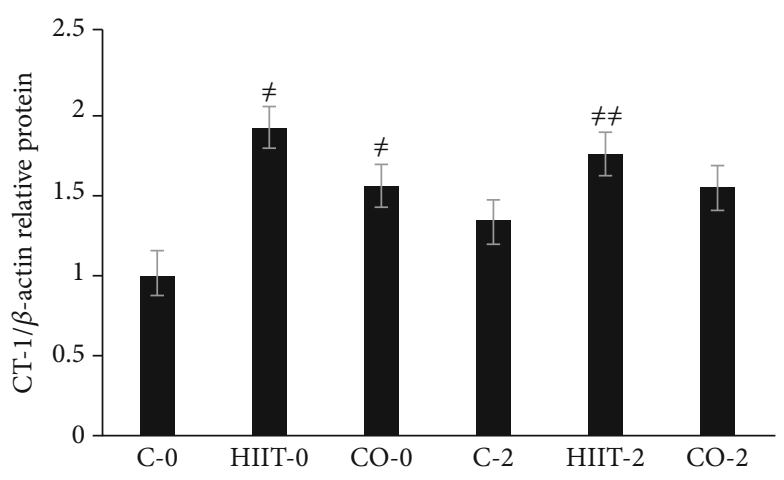

(c)

FIGURE 1: The impact of HIIT and CO exercise training on the (a) protein expressions of NO and CT-1 in the cardiac tissue of diabetic rats, (b) protein expression of NO, and (c) CT-1 proteins in different groups. The amount of rat $\beta$-actin used for normalizing the relative level of each protein, which expressed as the mean \pm SEM ( $n=3$ /group). ${ }^{\neq} p<0.01$ vs. control $(\mathrm{C}-0)$ group; ${ }^{\neq \neq} p<0.01$ vs. C-2 group animals.

0) after 8 weeks in rats with diabetes. Furthermore, CT-1 protein expression was significantly increased only in HIIT-2 compared to C-2 and CO-2. It has been suggested that CT1 induced glucose-stimulated insulin secretion [51]. Moreover, the injection of $\mathrm{CT}-1$ reversed insulin resistance in CT-1-deficient mice $[15,52]$, which considers the prominent role of CT-1 in the treatment of metabolic disorders and obesity. Another research showed that CT-1 values were substantially lower for overweight and obese subjects than those with normal weight [53]. In addition, although many types of research have been performed on the role of exercise and diabetes, our study seems to be the first to study that compares the role of HIIT and CO exercise on CT-1 in the heart muscle of diabetic mice. However, one study found that CT-1 values in athletes showed substantially higher in con- trast to the control group [22]. Another study reported no considerable difference in CT-1 levels after 8 to 10 percent weight loss [23]. One mechanism that may be involved in CT-1's insulin-sensitizing effects is its ability to oxidize FFA, as suggested by high levels of FFA increase insulin resistance in major organs of the body [54]. In this regard, the decrement of lipolytic genes and the lipolytic response has been found in CT-1 null mice, which stimulates body fat enhancement and insulin resistance $[55,56]$. On the other hand, due to the increase in CT-1 in individuals with metabolic syndrome and association with hyperglycemia, CT-1 appears to induce insulin resistance $[18,57]$. In contrast with this point, both HIIT and CO protocols increased CT-1 content that follows with an improvement of blood glucose levels in diabetics' animals. Moreover, it should be noted that HIIT 


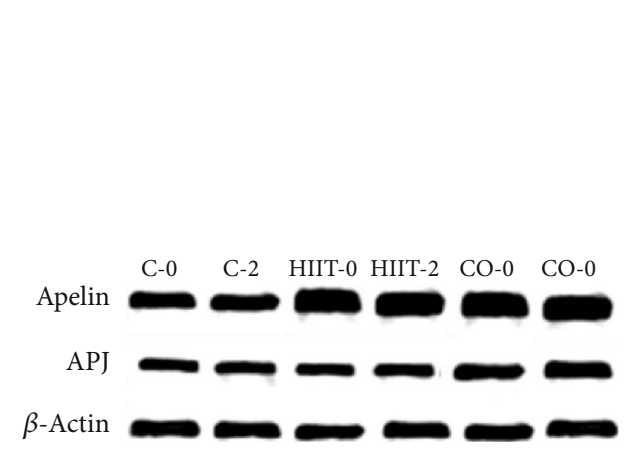

(a)

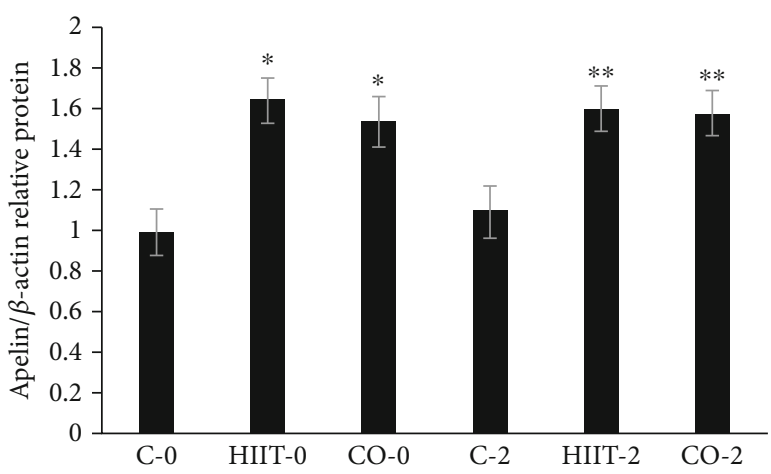

(b)

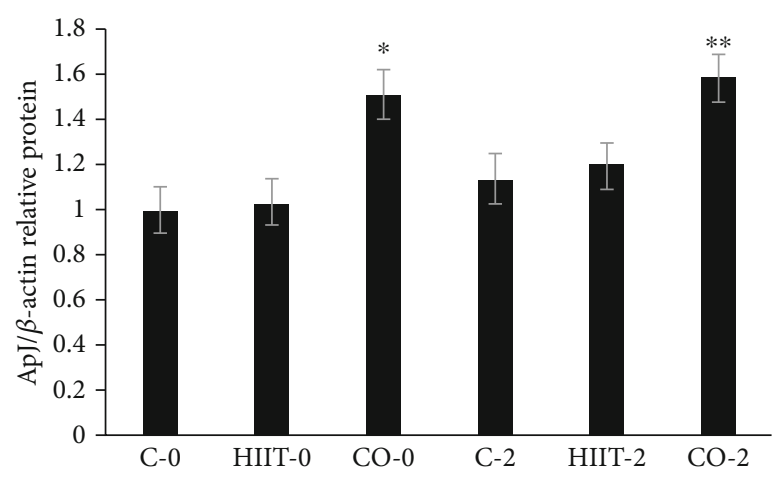

(c)

FIGURE 2: APJ and apelin protein values in the cardiac tissue $(\mathrm{a}-\mathrm{c})$. The amount of rat $\beta$-actin used for normalizing the relative level of each protein. Values are mean $\pm \mathrm{SD}(n=3$, for all groups); $* p<0.01$ vs. control (C-0) group; $* * p<0.01$ vs. C-2 group animals.

had a greater effect on CT-1 than $\mathrm{CO}$ in diabetic rats. However, the role of CT-1 in metabolism, obesity, and hyperglycemia in T2DM have been identified [32]. Nevertheless, the underlying biochemical/molecular mechanisms still need to be illuminated.

\section{Conclusion}

The current work investigates the effect of HIIT and CO protocols on apelin/APJ, NO, and cardiotrophin-1 in cardiac tissues in diabetic rats. We found that 8 weeks of HIIT and CO in rats with $\mathrm{T} 2 \mathrm{D}$ induced similar adaptations on apelin, APJ, NO, and cardiotrophin-1 in cardiac tissue. Moreover, the results also show the beneficial impacts of exercise in diabetics, despite its mode. However, strong supporting research is further needed.

\section{Data Availability}

The data used to support the findings of this study are available from the corresponding author upon request.

\section{Conflicts of Interest}

The authors declare no conflicts of interest.

\section{Acknowledgments}

We would like to thank the personnel of the University of Tehran for their help with the clinical portion of this study.

\section{References}

[1] R. Akclar, S. Turgut, V. Caner et al., "The effects of apelin treatment on a rat model of type 2 diabetes," Advances in Medical Sciences, vol. 60, no. 1, pp. 94-100, 2015.

[2] F. Yazdani, F. Shahidi, and P. Karimi, "The effect of 8 weeks of high-intensity interval training and moderate-intensity continuous training on cardiac angiogenesis factor in diabetic male rats," Journal of Physiology and Biochemistry, vol. 76, no. 2, pp. 291-299, 2020.

[3] G.-Q. Chen, C.-Y. Mou, Y.-Q. Yang, S. Wang, and Z.-W. Zhao, "Exercise training has beneficial anti-atrophy effects by inhibiting oxidative stress-induced MuRF1 upregulation in rats with diabetes," Life Sciences, vol. 89, no. 1-2, pp. 44-49, 2011.

[4] F. Kazemi and S. Zahediasl, "Effects of exercise training on adipose tissue apelin expression in streptozotocin-nicotinamide induced diabetic rats," Gene, vol. 662, pp. 97-102, 2018.

[5] Y. Habata, R. Fujii, M. Hosoya et al., "Apelin, the natural ligand of the orphan receptor APJ, is abundantly secreted in the colostrum," Biochimica et Biophysica Acta (BBA)-Molecular Cell Research, vol. 1452, no. 1, pp. 25-35, 1999.

[6] A.-M. O'Carroll, T. L. Selby, M. Palkovits, and S. J. Lolait, "Distribution of mRNA encoding B78/apj, the rat homologue of the human APJ receptor, and its endogenous ligand apelin in 
brain and peripheral tissues," Biochimica et Biophysica Acta (BBA)-Gene Structure and Expression, vol. 1492, no. 1, pp. 72-80, 2000.

[7] A. D. Medhurst, C. A. Jennings, M. J. Robbins et al., "Pharmacological and immunohistochemical characterization of the APJ receptor and its endogenous ligand apelin," Journal of Neurochemistry, vol. 84, no. 5, pp. 1162-1172, 2003.

[8] A. Reaux, K. Gallatz, M. Palkovits, and C. Llorens-Cortes, "Distribution of apelin-synthesizing neurons in the adult rat brain," Neuroscience, vol. 113, no. 3, pp. 653-662, 2002.

[9] A. Reaux, N. de Mota, I. Skultetyova et al., "Physiological role of a novel neuropeptide, apelin, and its receptor in the rat brain," Journal of Neurochemistry, vol. 77, no. 4, pp. 10851096, 2001.

[10] A. Noori-Zadeh, S. Bakhtiyari, S. Khanjari, K. Haghani, and S. Darabi, "Elevated blood apelin levels in type 2 diabetes mellitus: a systematic review and meta-analysis," Diabetes Research and Clinical Practice, vol. 148, pp. 43-53, 2019.

[11] J. Ishida, T. Hashimoto, Y. Hashimoto et al., "Regulatory roles for APJ, a seven-transmembrane receptor related to angiotensin-type 1 receptor in blood pressure in vivo," Journal of Biological Chemistry, vol. 279, no. 25, pp. 26274-26279, 2004.

[12] E. Ashley, H. J. Chun, and T. Quertermous, "Opposing cardiovascular roles for the angiotensin and apelin signaling pathways," Journal of Molecular and Cellular Cardiology, vol. 41, no. 5, pp. 778-781, 2006.

[13] J. Zhong, X. Yu, Y. Huang, L. Yung, C. Lau, and S. Lin, “Apelin modulates aortic vascular tone via endothelial nitric oxide synthase phosphorylation pathway in diabetic mice," Cardiovascular Research, vol. 74, no. 3, pp. 388-395, 2007.

[14] K. Tatemoto, K. Takayama, M.-X. Zou et al., "The novel peptide apelin lowers blood pressure via a nitric oxidedependent mechanism," Regulatory Peptides, vol. 99, no. 2-3, pp. 87-92, 2001.

[15] M. J. Moreno-Aliaga, N. Pérez-Echarri, B. Marcos-Gómez et al., "Cardiotrophin-1 is a key regulator of glucose and lipid metabolism," Cell Metabolism, vol. 14, no. 2, pp. 242-253, 2011.

[16] D. Pennica, K. L. King, K. J. Shaw et al., "Expression cloning of cardiotrophin 1, a cytokine that induces cardiac myocyte hypertrophy," Proceedings of the National Academy of Sciences of the United States of America, vol. 92, no. 4, pp. 1142-1146, 1995.

[17] D. Castaño, E. Larequi, I. Belza et al., "Cardiotrophin-1 eliminates hepatic steatosis in obese mice by mechanisms involving AMPK activation," Journal of Hepatology, vol. 60, no. 5, pp. 1017-1025, 2014.

[18] C. Natal, M. A. Fortuño, P. Restituto et al., "Cardiotrophin-1 is expressed in adipose tissue and upregulated in the metabolic syndrome," American Journal of Physiology-Endocrinology and Metabolism., vol. 294, no. 1, pp. E52-E60, 2008.

[19] D. Aune, T. Norat, M. Leitzmann, S. Tonstad, and L. J. Vatten, Physical Activity and the Risk of Type 2 Diabetes: a Systematic Review and Dose-Response Meta-Analysis, Springer, 2015.

[20] C. Y. Jeon, R. P. Lokken, F. B. Hu, and R. M. Van Dam, "Physical activity of moderate intensity and risk of type 2 diabetes: a systematic review," Diabetes Care, vol. 30, no. 3, pp. 744-752, 2007.

[21] W. Ji, L. Gong, J. Wang, H. He, and Y. Zhang, "Hypoxic exercise training promotes apelin/APJ expression in skeletal muscles of high fat diet-induced obese mice," Protein and Peptide Letters, vol. 24, no. 1, pp. 64-70, 2017.
[22] G. Limongelli, P. Calabrò, V. Maddaloni et al., "Cardiotrophin- 1 and TNF- $\alpha$ circulating levels at rest and during cardiopulmonary exercise test in athletes and healthy individuals," Cytokine, vol. 50, no. 3, pp. 245-247, 2010.

[23] R. Bowers, Changes in Cardiotrophin-1 and Fibroblast Growth Factor-21 with Weight Loss, Auburn University, 2009.

[24] S. G. Trost, N. Owen, A. E. Bauman, J. F. Sallis, and W. Brown, "Correlates of adults' participation in physical activity: review and update," Medicine \& Science in Sports \& Exercise, vol. 34, no. 12, pp. 1996-2001, 2002.

[25] N. Thomas, E. Alder, and G. Leese, "Barriers to physical activity in patients with diabetes," Postgraduate Medical Journal, vol. 80, no. 943, pp. 287-291, 2004.

[26] A. T. de Nardi, T. Tolves, T. L. Lenzi, L. U. Signori, and A. M. V. da Silva, "High-intensity interval training versus continuous training on physiological and metabolic variables in prediabetes and type 2 diabetes: a meta-analysis," Diabetes Research and Clinical Practice, vol. 137, pp. 149-159, 2018.

[27] C. Jelleyman, T. Yates, G. O'Donovan et al., "The effects of high-intensity interval training on glucose regulation and insulin resistance: a meta-analysis," Obesity Reviews, vol. 16, no. 11, pp. 942-961, 2015.

[28] Y. Liubaoerjijin, T. Terada, K. Fletcher, and N. G. Boulé, "Effect of aerobic exercise intensity on glycemic control in type 2 diabetes: a meta-analysis of head-to-head randomized trials," Acta Diabetologica, vol. 53, no. 5, pp. 769-781, 2016.

[29] C. J. Lavie, N. Johannsen, D. Swift et al., "Exercise is medicinethe importance of physical activity, exercise training, cardiorespiratory fitness and obesity in the prevention and treatment of type 2 diabetes," European Endocrinology, vol. 10, no. 1, pp. 18-22, 2014.

[30] J. B. Moreira, L. R. G. Bechara, L. H. M. Bozi et al., "High- versus moderate-intensity aerobic exercise training effects on skeletal muscle of infarcted rats," Journal of Applied Physiology, vol. 114, no. 8, pp. 1029-1041, 2013.

[31] Y. Burelle, R. B. Wambolt, M. Grist et al., "Regular exercise is associated with a protective metabolic phenotype in the rat heart," American Journal of Physiology-Heart and Circulatory Physiology, vol. 287, no. 3, pp. H1055-H1063, 2004.

[32] M. Nascimento, G. R. Punaro, R. S. Serralha et al., "Inhibition of the P2X7 receptor improves renal function via reninangiotensin system and nitric oxide on diabetic nephropathy in rats," Life Sciences, vol. 251, p. 117640, 2020.

[33] C. Bertrand, P. Valet, and I. Castan-Laurell, "Apelin and energy metabolism," Frontiers in Physiology, vol. 6, p. 115, 2015.

[34] M. B. Wysocka, K. Pietraszek-Gremplewicz, and D. Nowak, "The role of apelin in cardiovascular diseases, obesity and cancer," Frontiers in Physiology, vol. 9, p. 557, 2018.

[35] N. P. Kadoglou, I. S. Vrabas, A. Kapelouzou, and N. Angelopoulou, "The association of physical activity with novel adipokines in patients with type 2 diabetes," European Journal of Internal Medicine, vol. 23, no. 2, pp. 137-142, 2012.

[36] J. Zhang, C. X. Ren, Y. F. Qi et al., "Exercise training promotes expression of apelin and APJ of cardiovascular tissues in spontaneously hypertensive rats," Life Sciences, vol. 79, no. 12, pp. 1153-1159, 2006.

[37] C. Vinel, L. Lukjanenko, A. Batut et al., "The exerkine apelin reverses age-associated sarcopenia," Nature Medicine, vol. 24, no. 9 , pp. 1360-1371, 2018. 
[38] C. Dray, C. Knauf, D. Daviaud et al., "Apelin stimulates glucose utilization in normal and obese insulin-resistant mice," Cell Metabolism, vol. 8, no. 5, pp. 437-445, 2008.

[39] J. S. Son, H. J. Kim, Y. Son et al., "Effects of exercise-induced apelin levels on skeletal muscle and their capillarization in type 2 diabetic rats," Muscle \& Nerve, vol. 56, no. 6, pp. 1155-1163, 2017.

[40] H. Yang, L. Zhao, J. Zhang, C. S. Tang, Y. F. Qi, and J. Zhang, "Effect of treadmill running on apelin and APJ expression in adipose tissue and skeletal muscle in rats fed a high-fat diet," International Journal of Sports Medicine, vol. 36, no. 7, pp. 535-541, 2015.

[41] S. Sheibani, P. Hanachi, and M. A. Refahiat, "Effect of aerobic exercise on serum concentration of apelin, $\mathrm{TNF} \alpha$ and insulin in obese women," Iranian Journal of Basic Medical Sciences, vol. 15, no. 6, pp. 1196-1201, 2012.

[42] J. Krist, K. Wieder, N. Klöting et al., "Effects of weight loss and exercise on apelin serum concentrations and adipose tissue expression in human obesity," Obesity Facts, vol. 6, no. 1, pp. 57-69, 2013.

[43] J.-a. Kim, M. Montagnani, K. K. Koh, and M. J. Quon, “Reciprocal relationships between insulin resistance and endothelial dysfunction: molecular and pathophysiological mechanisms," Circulation, vol. 113, no. 15, pp. 1888-1904, 2006.

[44] M. Krause, J. Rodrigues-Krause, C. O'Hagan et al., "The effects of aerobic exercise training at two different intensities in obesity and type 2 diabetes: implications for oxidative stress, low-grade inflammation and nitric oxide production," European Journal of Applied Physiology, vol. 114, no. 2, pp. 251260, 2014.

[45] P. Newsholme, P. I. Homem de Bittencourt Jr., C. O' Hagan, G. de Vito, C. Murphy, and M. S. Krause, "Exercise and possible molecular mechanisms of protection from vascular disease and diabetes: the central role of ROS and nitric oxide," Clinical Science, vol. 118, no. 5, pp. 341-349, 2010.

[46] F. Moien-Afshari, S. Ghosh, S. Elmi et al., "Exercise restores endothelial function independently of weight loss or hyperglycaemic status in db/db mice," Diabetologia, vol. 51, no. 7 , pp. 1327-1337, 2008.

[47] M. Khazaei, F. Moien-Afshari, T. Kieffer, and I. Laher, "Effect of exercise on augmented aortic vasoconstriction in the $\mathrm{db} / \mathrm{db}$ mouse model of type-II diabetes," Physiological Research, vol. 57 , no. 6,2008 .

[48] N. Sallam, M. Khazaei, and I. Laher, "Effect of moderateintensity exercise on plasma C-reactive protein and aortic endothelial function in type 2 diabetic mice," Mediators of Inflammation, vol. 2010, 7 pages, 2010.

[49] C. U. Andersen, O. Hilberg, S. Mellemkjær, J. E. NielsenKudsk, and U. Simonsen, "Apelin and pulmonary hypertension,” Pulmonary Circulation, vol. 1, no. 3, pp. 334-346, 2011.

[50] V. Chavanelle, N. Boisseau, Y. F. Otero et al., "Effects of highintensity interval training and moderate-intensity continuous training on glycaemic control and skeletal muscle mitochondrial function in db/db mice," Scientific Reports, vol. 7, no. 1, article 204, 2017.

[51] A. Peters, "Incretin-based therapies: review of current clinical trial data," The American Journal of Medicine, vol. 123, no. 3, pp. S28-S37, 2010.

[52] J. Stephens, E. Ravussin, and U. White, "The expression of adipose tissue-derived cardiotrophin-1 in humans with obesity," Biology, vol. 8, no. 2, p. 24, 2019.
[53] H.-C. Hung, F.-H. Lu, H.-T. Wu et al., "Cardiotrophin-1 is inversely associated with obesity in non-diabetic individuals," Scientific Reports, vol. 5, no. 1, 2015.

[54] G. Boden, "Obesity and free fatty acids," Endocrinology and metabolism clinics of North America., vol. 37, no. 3, pp. 635646, 2008

[55] J. A. Villena, S. Roy, E. Sarkadi-Nagy, K.-H. Kim, and H. S. Sul, "Desnutrin, an adipocyte gene encoding a novel patatin domain-containing protein, is induced by fasting and glucocorticoids ectopic expression of desnutrin increases triglyceride hydrolysis," Journal of Biological Chemistry, vol. 279, no. 45, pp. 47066-47075, 2004.

[56] J. W. Jocken, D. Langin, E. Smit et al., “Adipose triglyceride lipase and hormone-sensitive lipase protein expression is decreased in the obese insulin-resistant state," The journal of Clinical Endocrinology \& Metabolism, vol. 92, no. 6, pp. 2292-2299, 2007.

[57] H.-C. Hung, F.-H. Lu, H.-Y. Ou et al., "Increased cardiotrophin-1 in subjects with impaired glucose tolerance and newly diagnosed diabetes," International Journal of Cardiology, vol. 169, no. 3, pp. e33-e34, 2013. 